\title{
Dairy Productivity and Technical Change: An Analysis of Confinement and Management Intensive Grazing Dairies in Maryland for 1995-2009
}

\author{
Kota Minegishi and Dale M. Johnson
}

\begin{abstract}
U.S. dairy production has been consolidating into large-scale confinement operations. Large numbers of small- to medium-scale dairies have disappeared in the last two decades, and many more are disappearing. This article analyzes small- to medium-scale dairy operations in Maryland during 1995-2009 for changes in technology and efficiency through a novel two-stage DEA approach to examine productivity changes. Conventional confinement dairy operations and management-intensive grazing dairies are analyzed separately. The results show that both dairy systems have become more productive on the technological frontiers, yet the rate of technical change for graziers was less than half the rate for confinement.
\end{abstract}

Key Words: dairy production, data envelopment analysis, management-intensive grazing, technical change, technical efficiency

The U.S. dairy industry has gone through significant structural changes in the last few decades and toward ever larger operations. The total output of milk has increased by 33 percent from 150.8 billion pounds in 1992 to 200.6 billion pounds in 2012, despite a 4.7 percent decline in the total stock of dairy cows. The innovations in milking, animal housing, improved animal care, and advances in dairy genetics have allowed some dairies to expand rapidly, whereas many dairies that remained at small scales chose to leave the industry (McDonald et al., 2007). The total number of dairy farms (with

Kota Minegishi is an assistant professor in the Department of Animal Science at University of Minnesota, Twin Cities. Dale M. Johnson is an extension specialist in the Department of Agricultural \& Resource Economics at University of Maryland, College Park. Correspondence: Kota Minegishi - 1364 Eckles Ave - Department of Animal Science at University of Minnesota, Twin Cities - Falcon Heights, MN 55108 - Phone 612.624.7455 - Email Kota@umn.edu.

An earlier draft of this article is a chapter of Kota Minegishi's dissertation at University of Maryland, College Park, and presented at 2013 Agricultural \& Applied Economics Association Meetings in Washington, D.C.

This work was supported by a joint research and extension program funded by the University of Maryland and Maryland Agricultural Experiment Station. We thank professor Robert Chambers for helpful comments. This study also benefited from the suggestions made by three anonymous referees. Any opinions, findings, conclusions, or recommendations expressed in this publication are those of the authors and do not necessarily represent the policies or views of any sponsoring agencies. Any error is our own.

Agricultural and Resource Economics Review 46/3 (December 2017) 555-578

(C) The Author(s) 2017. This is an Open Access article, distributed under the terms of the Creative

Commons Attribution licence (http://creativecommons.org/licenses/by/4.0/), which permits unrestricted re-use, distribution, and reproduction in any medium, provided the original work is 
20 or more cows) has declined by about 60 percent during 1992-2012, down to about 44,000 farms (USDA-NASS, 2012).

Amid the structural change, a movement to advance the ancient practice of grazing milk cows has emerged. Management-intensive grazing (MIG), or rotational grazing, as it is known in the dairy science literature, is a low-input, low-output dairy system with the potential to become a viable alternative to the small- to medium-scale conventional confinement operations. Compared to confinement dairies, MIG dairies rely less on feed purchases and mechanically harvested feed, two factors that help reduce the environmental footprint due to reduced soil erosion (DiGiacomo et al., 2001) and phosphorous run-off (Bishop et al. 2005). MIG dairies have lower capital requirements, also appealing for new entrants. The challenge for MIG dairies, on the other hand, is to meet the nutritional requirements of the herd. The producer must adhere to strict pasture management, primarily by rotating the animals among partitioned pasture paddocks on a daily basis to fully use the regenerative potential of pastures. Milk production per cow, along with the use of conventional inputs, substantially declines under MIG practices. Therefore, the economic competitiveness of MIG dairies depends on the relative decline in inputs to the decline in milk production, the relative prices of milk and production inputs, and the efficiency of the operation. Some studies suggest MIG dairies can be as competitive as confinement operations at relatively small scales (Elbehri and Ford 1995, Dartt et al. 1999, Gloy, Tauer, and Knoblauch 2002, Hanson et al. 2013). ${ }^{1}$

Whether it is a confinement or a MIG operation, the economic viability of most dairies likely depends on whether they can compete against a growing number of large-scale confinement operations. So far, the evidence that economies of scale are the main drivers of consolidating milk production is mixed; some studies found increasing returns to scale in dairy production (Tauer and Mishra 2006, Kumbhakar, Tsionas and Sipilinen 2009, Mosheim and Lovell 2009, Nehring et al. 2009), ${ }^{2}$ while others found otherwise (Byma and Tauer 2010, Cabrera, Solís and del Corral 2010, Mayen, Balagtas and Alexander, 2010, Mukherjee, Bravo-Ureta and De Vries 2013, Key and Sneeringer, 2014).

1 The relevant literature consists of field experiments in Minnesota (Rust et al., 1995), Virginia (Soriano, Polan, and Miller 2001), Mississippi (Tucker, Rude, and Wittayakun 2001), North Carolina (White et al., 2002), and Pennsylvania (Tozer et al., 2003) and economic analyses of data from Pennsylvania (Elbehri and Ford, 1995), Michigan (Dartt et al., 1999), New York (Gloy et al., 2002) and Maryland (Hanson et al., 2013).

2 Tauer and Mishra (2006) conclude that smaller farms can be competitive if they are technically efficient based on the smaller cost of size inefficiency compared to the cost of technical inefficiency. The analysis by Kumbhakar et al. (2009) on Finnish dairies with an average herd size of 31 cows has very limited relevance to U.S. dairies. The estimates of Mosheim and Lovell (2009) show relatively large effects of scale economies. A potential issue may be that the authors constructed a capital stock variable, which is central to their analysis, as net operating profits divided by the opportunity cost of capital. While it is deduced from economic theory, it appears at odds with the reality of fluctuating dairy income, depending on milk price. 
Nevertheless, the analysis of over 1500 operations with 500 or more cows by Nehring et al. (2009) presents the most compelling evidence of scale economies to this date. Greater clarity may be achieved by the research into the relationship between the emergence of large-scale confinement operations in certain production areas and the factors contributing to rapid dairy expansions such as the abundance of land, feed, and labor (Blayney 2002, McBride and Green 2009). If producers in certain regions are at a disadvantage in exploiting scale economies, the success of large-scale operations in places such as California, Washington, Idaho, New Mexico, and Florida would not be easily replicated elsewhere. This is particularly important for traditional dairy communities in the Upper Midwest and the Northeast, where many small- and medium-scale dairies have disappeared, but there has not been a dramatic expansion in large-scale confinement operations.

This article contributes to the ongoing discussions of structural change in the U.S. dairy industry by providing an analysis of technical change for confinement and MIG dairies that operated in Maryland during 1995-2009. The rate of technical change is a key indicator for the fundamental performance of the industry, and the comparison of this rate provides implications for the midterm prospects of the two dairy systems. Discussion of the affects of specific technological innovations that transformed dairy operations is beyond the scope of this article. Instead, our analysis is centered on the estimation of a technological frontier and its intertemporal shift. Building on the Malmquist Productivity Index (MPI) decomposition using data envelopment analysis (DEA; Färe et al. 1994), we devise a novel approach to decompositional measures that can be estimated from unbalanced panel data. Our estimation model, a variant of two-stage DEA analysis, also accounts for some noninput factors that may influence production outcomes. The article proceeds as follows: Section 2 describes the methodology, Section 3 presents the data and empirical analyses, and Section 4 concludes the study.

\section{Model}

\subsection{Measurement of Technical Change}

Consider a model of milk production $y_{i t}$ in which producer $i \in \mathbb{Q}=\{1, . ., I\}$ chooses L-dimensional inputs $\boldsymbol{x}_{i t}$ in time $t \in \mathbb{T}=\{1, \ldots, T\}$. A canonical representation of that model is

$$
y_{i t}=f_{t}\left(\boldsymbol{x}_{i t}\right) \cdot \exp \left(-u_{i t}+v_{i t}\right)
$$

where $f_{t}: \mathbb{R}_{+}^{L} \rightarrow \mathbb{R}_{+}$is the technological frontier in time $t$, $\exp \left(-u_{i t}\right)$ is multiplicative technical efficiency $T E_{i t} \in(0,1]$, and $\exp \left(v_{i t}\right)$ is a random error. 
Our interests are to analyze intertemporal structures of the technological frontier $f_{t}($.$) and the efficiency T E_{i t}$.

There are two major approaches to making equation (1) operational: parametric and semiparametric frontier models. In the parametric approach, the intertemporal patterns of a frontier and efficiency can be distinguished by imposing different functional assumptions. For instance, the pattern of frontier transitions may be specified as equiproportional shifts, in the forms of smooth interactions between the time variable and production inputs, or nonsmooth interactions via time-specific technological parameters. The pattern of efficiency may be modeled through a specific functional form (Battese and Coelli 1992, Cuesta 2000), a function of non- input-output variables (Battese and Coelli 1995), or producer-specific effects (Schmidt and Sickles 1984, Cornwell, Schmidt and Sickles, 1990, Kumbhakar 1990, Lee and Schmidt 1993, Karagiannis, Midmore and Tzouvelekas 2002, Roll 2013). The empirical challenge is to select appropriate specifications for these patterns that are both conceptually compelling for the case at hand and compatible with the data.

In the semiparametric approach, a prominent method is MPI decomposition using DEA (Färe et al., 1994). With its roots in the economic theory of production index numbers (e.g., Samuelson and Swamy 1974, Diewert 1976, Caves, Christensen and Diewert 1982), the MPI decomposition offers a general framework to analyze productivity trends such as those related to technical change. The method proceeds in two stages: in the first stage a semiparametric frontier is estimated separately for each time period, and technical efficiency is measured accordingly; in the second stage are obtained the shifts of the frontier and efficiency.

One shortcoming of the method is that its deterministic estimation (i.e., $\exp \left(v_{i t}\right)=0$ in (1)) can be sensitive to extreme data points and measurement errors. Another is that the method presumes a balanced panel data structure in calculating the producer-level MPI decomposition. Simply eliminating the data of producers whose observations are not available for the entire survey period can lead to biased estimates through nonrandom additions and attritions (Kerstens and Van de Woestyne, 2014).

The proposed estimation below is based on the MPI decomposition, while addressing the latter shortcoming. Specifically, to accommodate the use of unbalanced panel data, producer-level calculations of the MPI decomposition are replaced with a sample-level regression analysis of a frontier and efficiency. We derive statistical inferences based on the approach developed by Kneip, Simar and Wilson (2015) for the class of second-stage analysis estimators on DEA efficiency measures.

\subsection{Two-stage Analysis of Distance Functions}

Central to the MPI decomposition are the concepts of the distance between a production decision (i.e., an input-output bundle) and a technological frontier 
and the distance between two technological frontiers of two time periods. These distances are analyzed in two stages.

A conceptual framework is provided through the three types of distances that are derived from technical/pseudotechnical efficiency measurements. The output-oriented technical efficiency is the relative distance between decision $\left(\boldsymbol{x}_{i t}, y_{i t}\right)$ and frontier $f_{t}($.$) , or T E_{i t} \equiv y_{i t} / f_{t}\left(\boldsymbol{x}_{i t}\right)$. The envelopment of $f_{t}($.$) across$ time $t \in \mathbb{T}$ is referred to as a metafrontier (Battese, 2002; Battese, Rao, and O'Donnell 2004) representing the maximum attainable outputs of all time periods $\mathbb{T}$, or $f^{M}(\boldsymbol{x})=\max _{t \in \mathbb{T}}\left\{f_{t}(\boldsymbol{x})\right\}$. Then, two pseudotechnical efficiency measures are obtained: the technological gap ratio (TGR) defined for the relative distance between the time- $t$ frontier and the metafrontier, or $T G R_{i t} \equiv$ $f_{t}\left(\boldsymbol{x}_{i t}\right) / f^{M}\left(\boldsymbol{x}_{i t}\right)$, and the metatechnological efficiency (MTE), defined as the relative distance between the decision and the metafrontier, or $M T E_{i t} \equiv$ $y_{i t} / f^{M}\left(\boldsymbol{x}_{i t}\right)^{3}$

Figure 1 illustrates these concepts in a single-input single-output case; the three distance measurements for decision $\left(\boldsymbol{x}_{i t}, y_{i t}\right)$ are depicted as $T E_{i t}=$ $A Q / B Q, M T E_{i t}=A Q / C Q$, and $T G R_{i t}=B Q / C Q$. Note that $M T E_{i t}=T G R_{i t} \cdot T E_{i t}{ }^{4}$ and the intertemporal change of MTE provides a version of the MPI decomposition; $\Delta_{t} \ln M T E_{i t}=\Delta_{t} \ln T G R_{i t}+\Delta_{t} \ln T E_{i t}$ where $\Delta_{t} \ln M T E_{i t}$ (i.e., an intertemporal, percentage change in MTE) is a measure of productivity change, $\Delta_{t} \ln T G R_{i t}$ is a measure of technical change (TC), and $\Delta_{t} \ln T E_{i t}$ is a measure of technical efficiency change (TEC).

In the first stage, we approximate time-t frontiers by DEA. ${ }^{5}$ Under the nonincreasing returns to scale (NIRS) assumption, ${ }^{6}$ the DEA approximation to the technology (i.e., a set of all technically feasible input-output bundles) is the smallest free-disposal convex hull that envelops relevant data points of input-output decisions, including the origin. Under the assumption $v_{i t}=0$ in equation (1), the boundary of that approximation is the estimate of technological frontier defined by

3 Recent applications of TGR include productivity comparisons of aggregate agricultural outputs across 97 countries (O'Donnell, Rao and Battese, 2008), banking industries in China and Taiwan during 1993-2007 (Chen and Song, 2008), and farm-level dairy production in Argentina, Chile, and Uruguay (Moreira and Bravo-Ureta, 2010). While most of these applications use Stochastic Frontier Analysis (SFA), O'Donnell, Rao and Battese (2008) formalize the concept of metatechnology with the distance function and apply it to both DEA and SFA analyses.

4 A possible extension is to include scale efficiency (SE) in the decomposition; $M T E_{i t}=T G R_{i t} \cdot S E_{i t} \cdot T E_{i t}$ where $S E_{i t}=f^{V R S}\left(\boldsymbol{x}_{i t}\right) / f^{C R S}\left(\boldsymbol{x}_{i t}\right)$, or the ratio of frontier outputs under constant and variable returns to scale, and $T E_{i t}=y_{i t} / f^{V R S}\left(\boldsymbol{x}_{i t}\right)$. Subsequently, $\ln S E_{i t}$ may be analyzed in a regression similar to the one for $\ln T G R_{i t}$.

5 In Appendix B, we consider alternative specifications using parametric frontiers.

6 Replacing constraint $\sum_{j}^{I} \lambda_{j} \leq 1$ with equality yields a variable returns to scale (VRS) technology, whereas omitting the constraint yields a constant returns to scale (CRS) technology. NIRS and VRS yield more conservative estimates of technology than CRS. VRS, however, is not always compatible with out-of-sample technical efficiency measurement used in the MPI calculation. 


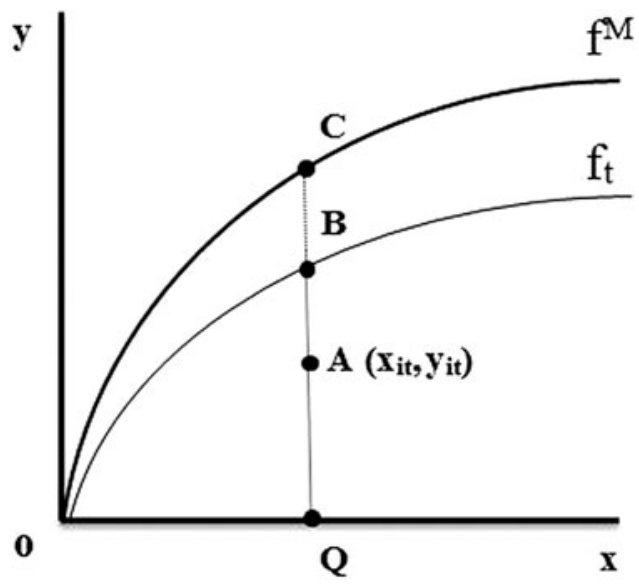

Figure 1. Time-specific frontiers and the meta-Frontier

$$
\begin{aligned}
\forall \boldsymbol{x}^{\prime} & \in R_{+}^{L}, \widehat{f}\left(\boldsymbol{x}^{\prime}\right) \\
& =\max _{\lambda \in R_{+}^{N}}\left\{y^{\prime} \in R_{+}: \sum_{j=1}^{N} \lambda_{j} \boldsymbol{x}_{j} \leq \boldsymbol{x}^{\prime}, \quad \sum_{j=1}^{N} \lambda_{j} y_{j} \geq y^{\prime}, \quad \sum_{j}^{N} \lambda_{j} \leq 1\right\}
\end{aligned}
$$

for cross-sectional data of $N$ observations. Based on (2), we obtain time- $t$ frontier $f_{t}($.$) using N_{t}$ reference data points in time $t \in \mathbb{T}$. Given the relatively small sample size, we modify (2) with the assumption of no technological regress, implemented through the constraint $f_{t}(.) \geq f_{t-1}($.$) for t=2, \ldots, T .^{7}$ Enveloping all such frontiers $f_{t}($.$) across time t \in T$ yields our estimate of meta-frontier $f^{M}($.).

In the second stage, the above distance measurements are analyzed in a system of linear equations. By ordinary least squares (OLS), we estimate

$$
\begin{aligned}
& \ln \widehat{T G R}\left(\boldsymbol{x}_{i t}, y_{i t} ; t\right)=\boldsymbol{z}_{i t} \boldsymbol{\delta}^{T G R}+\boldsymbol{w}_{i t} \gamma^{T G R}+\beta_{0}^{T G R}+\beta_{1}^{T G R} t+\varepsilon_{i t}^{T G R} \\
& \ln \widehat{T E}\left(\boldsymbol{x}_{i t}, y_{i t} ; t\right)=\boldsymbol{z}_{i t} \boldsymbol{\delta}^{T E}+\boldsymbol{w}_{i t} \gamma^{T E}+\beta_{0}^{T E}+\beta_{1}^{T E} t+\varepsilon_{i t}^{T E} \\
& \boldsymbol{\delta}_{t}^{M T E} \equiv \boldsymbol{\delta}_{t}^{T G R}+\boldsymbol{\delta}_{t}^{T E}, \boldsymbol{\gamma}_{t}^{M T E} \equiv \boldsymbol{\gamma}_{t}^{T G R}+\boldsymbol{\gamma}_{t}^{T E}, \beta_{l}^{M T E} \equiv \beta_{l}^{T G R}+\beta_{l}^{T E} \text { for } l \in\{0,1\}
\end{aligned}
$$

where $\widehat{T G R}\left(\boldsymbol{x}_{i t}, y_{i t} ; t\right)$ is the efficiency of time- $t$ frontier relative to the metafrontier; $\widehat{T E}\left(x_{i t}, y_{i t} ; t\right)$ is the efficiency of decision it relative to the time- $t$ frontier; $\boldsymbol{z}_{i t}$ is producer-specific characteristics; $\boldsymbol{w}_{i t}$ is environmental

7 This amounts to estimating $f_{t}($.$) by referencing \sum_{k=1}^{t} N_{k}$ data points in time $\forall k \leq t$. Under no technological regress, $f^{M}()=.f_{T}($.) for the final time period $T$. 
variables; [ $\boldsymbol{\delta} \gamma \beta_{0} \beta_{1}$ ] are parameters to be estimated; and $\varepsilon_{i t}^{*}$. is an error term. We set $\boldsymbol{\delta}_{t}^{T G R} \equiv 0$ since, conceptually, producer characteristics $\boldsymbol{z}_{i t}$ do not alter the definition of underlying technical feasibility in the input-output decision. Additionally, to mitigate the potential bias of producer characteristics $\boldsymbol{z}_{i t}$ that apparently influence efficiency through the choices of inputs $\boldsymbol{x}_{i t}$ (Johnson and Kuosmanen 2011), we use the orthogonal projection of $\boldsymbol{z}_{i t}$ on $\boldsymbol{x}_{i t}$ as regressors. ${ }^{8}$ The parameters for $\widehat{M T E}\left(x_{i t}, y_{i t} ; T\right)$ in the last line follow from the identity $M T E_{i t}=T G R_{i t} \cdot T E_{i t}$. Then, specification (3) yields a version of sample-level MPI decomposition

$$
E[\ln M P I] \equiv \beta_{1}^{M T E}, E[\ln T C] \equiv \beta_{1}^{T G R}, E[\ln T E C] \equiv \beta_{1}^{T E}
$$

that can be estimated from unbalanced panel data or repeated cross-sectional data.

The OLS estimate of equation (3) is statistically consistent, given the consistent estimates of $T G R_{i t}$ and $T E_{i t}$ and the orthogonality of error terms $E\left[\varepsilon_{i t}^{T G R} \mid \boldsymbol{w}_{i t}, t\right]=0$ and $E\left[\varepsilon_{i t}^{T E} \mid \boldsymbol{z}_{i t}, \boldsymbol{w}_{i t}, t\right]=0$. The estimate would be, however, biased because the first-stage estimates of $T G R_{i t}$ and $T E_{i t}$ are biased due to a finite sample property of the DEA frontier approximation (i.e., the most efficient decisions in the universe are likely unobserved in a finite sample). To address this issue, we employ the bias-correction technique of Kneip, Simar and Wilson (2015) that exploits the difference in convergence rates between DEA estimators under the full sample and subsamples in the following section.

\subsection{Statistical Inferences}

Statistical inferences are derived in three steps. First, through the TE equation of (3), we correct for the finite-sample bias of the first-stage DEA. Second, given the bias correction, we obtain the estimates of frontiers $f_{t}, f^{M}$ and their ratio TGR $(. ; t)=f_{t} / f^{M}$. Third, we estimate the full model of (3), while accounting for serially and contemporary correlated errors. Note that in the third step the measurement errors in dependent variables would reduce the estimation precision but do not cause bias.

Following Kneip, Simar and Wilson (2015), we correct for the bias in the

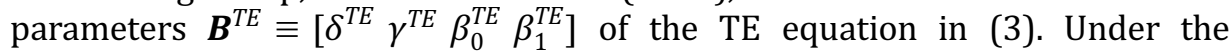
homoskedasticity of the error term and the so-called separability assumption (that producer characteristics $\boldsymbol{z}_{i t}$ do not shift the underlying technological frontier $f_{t}$ ) along with the regularity conditions described in that article, the limiting distribution of $\widehat{\boldsymbol{B}}^{T E}$ can be expressed as

8 Monte Carlo evidence for its effectiveness is available from the authors. 


$$
\bar{N}^{\kappa}\left(\widehat{\boldsymbol{B}}^{T E}-\boldsymbol{B}^{T E}-\boldsymbol{Q}^{-1} \boldsymbol{C} \bar{N}^{-\kappa}-\boldsymbol{R}_{\bar{N}, \kappa}\right) \stackrel{L}{\rightarrow} N\left(\mathbf{0}, \sigma^{2} \boldsymbol{Q}\right)
$$

where $\bar{N}=\sum_{t \in T} N_{t} / T$ is the average sample size of DEA-frontier estimations across time periods; $\boldsymbol{Q}=E\left[(\boldsymbol{Z} \boldsymbol{Z})^{-1}\right]$ is the variance-covariance matrix of $\boldsymbol{Z}$; $\kappa=2 /(L+M+1)$ is a constant given the dimension of input-output variables $L+M ;^{9} \boldsymbol{C}$ is the set of constants that represent upper bounds of the finitesample bias, and $\boldsymbol{R}_{\bar{N}, k}$ is the remainder. The theoretical rate of convergence is $\bar{N}^{\kappa}$ when $\kappa \leq 1 / 2$ and $\bar{N}^{1 / 2}$ otherwise.

Subtracting a consistent estimate of the bias term $\boldsymbol{Q}^{-1} \boldsymbol{C} \overline{\boldsymbol{N}}^{-\kappa}$ from $\widehat{\boldsymbol{B}}^{T E}$ yields an unbiased estimator

$$
\widehat{\mathfrak{B}}^{T E}=\widehat{\boldsymbol{B}}^{T E}-\left(2^{\kappa}-1\right)^{-1}\left(\widehat{\boldsymbol{B}}_{\bar{N} / 2}^{T E^{*}}-\widehat{\boldsymbol{B}}^{T E}\right)
$$

where $\widehat{\boldsymbol{B}}_{\bar{N} / 2}^{T E *}$ is a jackknife estimate of $\boldsymbol{B}^{T E}$ using a subsample $\mathcal{X}_{\bar{N} / 2}$ of size $\bar{N} / 2$ drawn from the sample $\mathcal{X}_{\bar{N}}=\left\{\left(\boldsymbol{x}_{i t}, y_{i t}\right)\right\}_{i \in I, t \in T}$. Following the authors' approach, we use randomly partitioned half samples $\mathcal{X}_{\bar{N} / 2}^{(1)}$ and $\mathcal{X}_{\bar{N} / 2}^{(2)}$ and the corresponding partitioning of $\boldsymbol{Z}$, which yields $\widehat{\mathbf{B}}_{\bar{N} / 2}^{T E^{*}} \equiv\left(\mathbf{Z}^{\prime} \mathbf{Z}\right)^{-1}\left(\mathbf{Z}_{\bar{N} / 2}^{(1)^{\prime}} \ln \widehat{T E}_{\bar{N} / 2}^{(1)}+\right.$ $\left.\boldsymbol{Z}_{\bar{N} / 2}^{(2)^{\prime}} \ln \widehat{T E}_{\bar{N} / 2}^{(2)}\right)^{10}$

Next, bias-corrected TE and TGR measurements are derived. Let the bias-corrected TE be $\widehat{\mathfrak{I E}}_{i t} \equiv \exp \left(\ln \widehat{T E}_{i t}-\widehat{\operatorname{bias}}\left(\mathbf{z}_{i t}, \boldsymbol{w}_{i t}, 1, t\right)\right)$, where the bias is the product of the estimated bias in coefficients and the corresponding variables. Then we obtain $\widehat{\mathfrak{f}}_{t}\left(\boldsymbol{x}_{i t}\right) \equiv y_{i t} / \widehat{\mathfrak{I}}_{i t}, \hat{\mathfrak{f}}^{M}\left(\boldsymbol{x}_{i t}\right) \equiv \max _{t \in T}\left\{\hat{\mathfrak{f}}_{t}\left(\boldsymbol{x}_{i t}\right)\right\}$, and $\widehat{\mathfrak{I}(\mathfrak{F R}}_{i t} \equiv \hat{\mathfrak{f}}_{t} / \hat{\mathfrak{f}}^{M}$.

Finally, we regress $\widehat{\mathfrak{T E}}_{i t}$ and $\widehat{\mathfrak{T C R}}_{i t}$ according to the second-stage model (3). In our application, error terms $\varepsilon_{i t}^{T E}$ and $\varepsilon_{i t}^{T G R}$ are likely serially correlated across time periods among producers and, to a lesser extent, contemporaneously correlated within a production year. We apply the Prais-Wenstein transformation to accommodate an autoregressive process (AR(1)) and cluster standard errors at each production year to address these issues.

\section{Application}

\subsection{Data}

We use unbalanced panel data on annual revenues and expenses of 63 dairy farms that operated in Maryland or near its state border with Pennsylvania

\footnotetext{
$9 \kappa=2 /(L+M)$ for constant returns to scale. Our model is $M=1$.

10 We draw half samples containing half the number of observations in each time period. We use the average results of 100 repetitions.
} 
during 1995-2009. The dataset, derived from individual farmer's tax return form Schedule F, is a nonrandom sample but representative of the state of Maryland and has been previously analyzed by Hanson et al. (2013). Each operation is categorized as either a conventional confinement dairy or MIG dairy, referred to as confinement or grazier, respectively. Grazing operations tend to be smaller than their confinement counterparts in terms of herd size and milk output per cow. The relative profitability of the two systems varies across production years and producers, depending on the prices in relevant agricultural markets and the technical efficiency of individual producers.

On average, however, no statistically significant difference is found in their profits (Hanson et al., 2013). The two dairy systems may be directly comparable in budget analyses but not in production analyses, for which production inputs must be relatively homogeneous. Given the different breeds of cows and capital equipment used by the confinement and graziers, we analyze the two systems of dairy operations separately. ${ }^{11}$ There are four farms that have switched from confinement to grazing during the survey period, but their influence on our analysis is very small. ${ }^{12}$ As an observational study, the possibility that farms of certain characteristics might have selected into grazing is beyond our control. However, its influence on our analysis would be limited because most farms in our data are relatively small and similar in their backgrounds and operating environments.

Given the scarcity of economic data on MIG operations, to our knowledge the current analysis is the first study to compare the productivity of confinement and graziers over a relatively long time period. The long time horizon is particularly important to studying dairy productivity, which is affected by fluctuating weather conditions and market prices over time. Our data set is focused on a particular geographic location, which means that the data consist of highly comparable farms of a relatively small sample size. It is unbalanced panel data, given the entry and exit from our survey, that contain the average of 20.9 confinement and 10.7 grazing farms per year. ${ }^{13}$ The sample size limits the scope of input-output variable specification and reduces the precision of the analysis. However, for the purpose of examining the trends in productivity, the total sample size of 314 confinement and 161 grazier data-points appears sufficient, and our robustness analysis shows consistent results in general (see Appendix A).

\footnotetext{
11 The failure to account for the precise composition of breeds may reduce the accuracy of efficiency analysis for graziers. Some graziers were still in transition by gradually altering the herd composition in the early years of the study period.

12 Dairy farms rarely switch between grazing and confinement operations, given transition costs.

13 The numbers of graziers in our data is $4,7,8,9,9,11,11,11,12,12,12,14,15,14,12$ for years 1995-2009. Year 1996, instead of 1995, is used as a base year for this group.
} 
We specify milk production $\left(y_{i t}\right)^{14}$ with four inputs $\left(\boldsymbol{x}_{i t}\right)$ : herd size, capital equivalent, crop acreage, and pasture acreage. Capital equivalent is defined as the total dairy expenditure deflated by an observation-specific production cost index, which is the share-weighted average of price indices that correspond to expense items. Price indices are obtained from the Prices Paid Indexes of National Agricultural Statistical Service, USDA. The total expenditure is the sum of all expenses in Schedule F, including expenses for feed purchases and feed production, veterinary care, hired labor, fuels and maintenance, and user-costs of capital such as rents, interests, and depreciation of buildings and machinery. Note that the labor expense, which does not account for unpaid labor and is less than 5 percent of the total production cost in our data, is included in the capital equivalent variable. With regard to the use of Schedule $\mathrm{F}$ data, changes in inventories may introduce measurement errors in the reported annual expenses for crop production. ${ }^{15}$ Nonetheless, it is unlikely to cause substantial bias in our analysis for the dairy productivity trends over a 15-year period. Statistical properties of the milk output and input variables are presented in Table 1. For the second-stage regressions, we include binary indicators of farmownership and off-farm income $\left(\boldsymbol{z}_{i t}\right)$ and a regional heat index $\left(\boldsymbol{w}_{i t}\right)^{16}$

Table 2 shows the average production data by dairy system and calendar year. The average production of confinement dairies has nearly doubled from 1.53 million pounds of milk in 1995 to 3.04 million pounds in 2009, which can be attributed to the increased scale of operation from 85 cows to 150 cows and a 8.6 percent increase in output per cow from 18,300 pounds to 19,900 pounds. The increase in herd size was matched by an increase in capital input of similar proportion, while few changes occurred in land acreage used for crop production and pasture at around 300 acres and 50 acres, respectively.

In contrast, milk output for an average grazing operation has remained stable at around 1.30 million pounds, despite an increase in herd size from 79 cows to 101 cows. Due to the small sample size of this group, the average production fluctuates with entries and exits in our data (i.e., likely the cause of the apparent dip in production in 2005). Overall, grazier's milk output per cow has declined by 28.3 percent from 17,300 pounds to 12,400 pounds, along

\footnotetext{
14 Milk output used in this article does not account for the quality difference in milk, including organic certification that applies to a handful of MIG operations in the dataset. The sales of animals and crops, which account for less than 15 percent of the total revenue, are also excluded from the output. The analysis using the total revenue from milk, cattle, and crop sales yields qualitatively similar results.

15 Barnard, Ellinger and Wilson (2010) point to the possibility that the reported expenses in Schedule $F$ may not correspond to the actual input decisions of that year when farms accumulate or sell inventories or use accelerated depreciation methods for tax purposes.

16 In our sample, 91.1 percent of confinement and 71.4 percent graziers owned the farm, and 6.7 percent of confinement and 21.1 percent of graziers had some off-farm income. The heat index is the number of days above 30 degrees Celsius (based on the daily maximum temperature at Martinsburg Eastern Regional Airport), which varies with time but is fixed across producers.
} 
Table 1. Summary Statistics of Production Variables

\begin{tabular}{|c|c|c|c|c|c|c|c|c|}
\hline \multirow[b]{2}{*}{ Variable } & \multicolumn{4}{|c|}{ Confinement (Obs. 314) } & \multicolumn{4}{|c|}{ Graziers (Obs. 161) } \\
\hline & Mean & S.D. & Min & Max & Mean & S.D. & Min & Max \\
\hline Milk (million pounds) & 2.41 & 1.76 & 0.38 & 11.07 & 1.24 & 0.56 & 0.27 & 4.30 \\
\hline Capital Equivalent & 416 & 308 & 71 & 1,781 & 205 & 92 & 58 & 645 \\
\hline Cow & 122 & 76 & 22 & 468 & 87 & 29 & 37 & 195 \\
\hline Crop Acre & 289 & 155 & 60 & 704 & 132 & 108 & 0 & 600 \\
\hline Pasture Acre & 50 & 39 & 0 & 141 & 152 & 60 & 53 & 280 \\
\hline
\end{tabular}

Capital equivalent is the total cost of production $(\$ 1,000)$, deflated by a farm production cost index (2009 base). For more information on the dataset, see Hanson et al. (2013). 
Table 2. Average Production Practices By Dairy System and Year, Selected Years

\begin{tabular}{lcccccc}
\hline Year & N.Obs & Milk (M lb) & Cows & Capital Eq. & $\begin{array}{c}\text { Crop } \\
\text { Acre }\end{array}$ & $\begin{array}{c}\text { Pasture } \\
\text { Acre }\end{array}$ \\
\hline $\begin{array}{l}\text { Confinement } \\
1995\end{array}$ & 21 & 1.53 & 85 & 256 & 273 & 55 \\
2000 & 21 & 2.46 & 121 & 404 & 292 & 48 \\
2005 & 22 & 2.76 & 137 & 498 & 297 & 51 \\
2009 & 19 & 3.04 & 150 & 505 & 316 & 53 \\
Graziers & & & & & & \\
1996 & 7 & 1.36 & 79 & 208 & 133 & 165 \\
2000 & 11 & 1.33 & 85 & 215 & 130 & 164 \\
2005 & 12 & 1.11 & 84 & 182 & 109 & 144 \\
2009 & 12 & 1.32 & 101 & 211 & 138 & 135 \\
\hline
\end{tabular}

Graziers had only four observations in 1995, and hence year 1996 is shown as a base year for this group.

with a slight reduction in pasture acreage from 165 acres to 135 acres. Notably, the assumption of equiproportional shifts in production frontiers, known as the Hicks-neutral technical change, is unlikely to hold for these transitions. The analysis in the following section looks beyond these changes in average inputs and outputs to investigate underlying changes in technology and efficiency.

\subsection{Results}

In Table 3, we summarize the first-stage estimation results for meta-technical efficiency (MTE) against the meta-frontier, technical efficiency (TE) against year-specific frontiers, and technology gap ratios (TGR) as the ratio of the two. At the median of these estimates, confinement and MIG producers are 83.6 percent and 74.5 percent efficient respectively in a given year and 76.6 percent and 69.3 percent efficient, compared to their all-time, meta-frontiers.

Table 4 contains the second-stage estimation results for confinement in columns (1)-(2) and for graziers in columns (3)-(4). The coefficients represent marginal effects in percentage-points. The estimates of linear time trends indicate, on average, TGR grew 1.21 percent per year and TE declined -0.56 percent per year for confinement operations. This translates into the MPI decomposition of a 0.65 percent annual growth of MPI that consists of 1.21 percent TC (technological progress) and -0.56 percent TEC (declines in technical efficiency). Similarly, the estimates for graziers translate into a 1.22 percent annual decline of MPI that decomposes to 0.59 percent TC and -1.81 percent TEC. These estimates are generally robust to alternative assumptions under panel-consistent standard errors, potential 
Table 3. Summary of DEA Efficiency and TGR Scores

\begin{tabular}{|c|c|c|c|c|c|c|}
\hline \multirow[b]{2}{*}{ System } & \multicolumn{6}{|c|}{ Summary Statistics } \\
\hline & Min & 25th & Median & Mean & 75th & Max \\
\hline \multicolumn{7}{|c|}{ A. Efficiency at meta-frontiers (MTE) } \\
\hline (1) Confinement & 0.380 & 0.709 & 0.766 & 0.770 & 0.839 & 0.942 \\
\hline (2) Graziers & 0.315 & 0.617 & 0.693 & 0.699 & 0.809 & 0.916 \\
\hline \multicolumn{7}{|c|}{ B. Efficiency at year-specific frontiers (TE) } \\
\hline (3) Confinement & 0.434 & 0.750 & 0.834 & 0.822 & 0.908 & 0.942 \\
\hline (4) Graziers & 0.315 & 0.630 & 0.745 & 0.732 & 0.858 & 0.926 \\
\hline \multicolumn{7}{|c|}{ C. Technology Gap Ratios (TGR) } \\
\hline (5) Confinement & 0.710 & 0.905 & 0.957 & 0.937 & 0.982 & 1.000 \\
\hline (6) Graziers & 0.736 & 0.939 & 0.978 & 0.959 & 1.000 & 1.000 \\
\hline
\end{tabular}

1. Technical efficiencies (TE) and meta-technical efficiency (MTE) are measured against year-specific frontiers and meta-frontiers respectively. Technology gap ratio (TGR) is the ratio of those efficiency measurements (i.e., MTE/TE) at observation level.

2. The reported results are obtained with the bias-correction discuss in the methodology section. 
Table 4. Estimation Results for the Determinants of Productivity

\begin{tabular}{|c|c|c|c|c|}
\hline & \multicolumn{2}{|c|}{ Confinement } & \multicolumn{2}{|c|}{ Graziers } \\
\hline & (1) & (2) & (3) & (4) \\
\hline & In TGR & $\ln \mathrm{TE}$ & In TGR & $\ln \mathrm{TE}$ \\
\hline \multirow[t]{2}{*}{ Year } & $1.21^{* * *}$ & $-0.56^{* * *}$ & $0.59^{* * *}$ & $-1.81^{* * *}$ \\
\hline & $(0.13)$ & $(0.12)$ & $(0.07)$ & $(0.27)$ \\
\hline \multirow[t]{2}{*}{ Heat Index } & -0.16 & 0.35 & -0.12 & -0.81 \\
\hline & $(0.26)$ & $(0.43)$ & $(0.21)$ & $(0.94)$ \\
\hline \multirow[t]{2}{*}{ Farm Ownership } & & $3.16^{* *}$ & & $7.08^{* *}$ \\
\hline & & $(1.29)$ & & $(3.05)$ \\
\hline \multirow[t]{2}{*}{ Off-farm Income } & & $-5.40^{* *}$ & & -3.62 \\
\hline & & $(2.12)$ & & $(3.36)$ \\
\hline \multirow[t]{2}{*}{ Constant } & $-2431.94^{* * *}$ & $1102.91^{* * *}$ & $-1188.00^{* * *}$ & $3593.15^{* * *}$ \\
\hline & (259.46) & $(238.60)$ & (142.35) & (547.59) \\
\hline Adj. R Squared & 0.836 & 0.599 & 0.427 & 0.583 \\
\hline
\end{tabular}

1. Standard errors in parentheses. Statistical significance: ${ }^{* * *} \alpha=0.01,{ }^{* *} \alpha=0.05,{ }^{*} \alpha=0.1$.

2. Heat index is the number of days above 30 degrees Celsius, divided by 10 .

3. Dependent variables (ln TGR and ln TE) are scaled by the factor of 100, so that the marginal effects are presented in percentage terms.

technological regress, omission of the bias-correction step, and constant returns to scale specifications (see Appendix A).

To examine year-by-year changes in technology and efficiency, we additionally estimate a specification with year fixed effects. We plot the estimated fixed effects in Figure 2 along with its 95 percent confidence intervals and linear trends. The result shows that the year fixed-effects generally follow linear trends, particularly for confinement producers.

The positive technical change and increasing efficiency gaps in both systems suggest that some producers have successfully adopted new technologies and improved their management, while others have struggled to keep up with these changes. In particular, the different trends observed for the two systems seem to indicate that a greater share of confinement operations have benefitted from recent technological advances, compared to graziers. This is consistent with a common perception that confinement dairy operations generally follow standardized industry production techniques, while MIG operations involve highly localized and idiosyncratic production practices (mainly due to local soil and microclimate conditions that require experimentation by individual producers). ${ }^{17}$

\footnotetext{
17 See, for example, Khanal, Gillespie and MacDonald. (2010) for recent technological adoption in the US dairy sector. Discussions on the improvement of rotational grazing are found in Kriegel and Frank (2005); Taylor and Foltz (2006); Winsten et al. (2010); Nelson et al. (2014).
} 

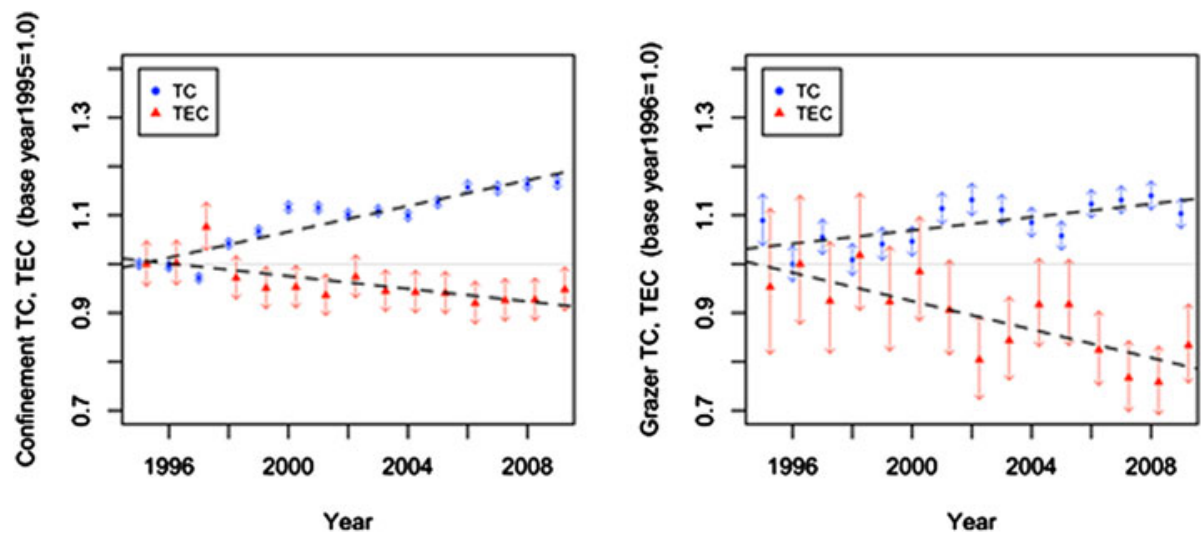

\section{Figure 2. Technical change and technical efficiency change}

Declining technical efficiency for both groups means that the productivity gaps among dairy producers are increasing. Dairy producers traditionally have pursued expansions and upgrades in times of high milk prices. However, with the emergence of ever-larger, capital-intensive operations, the standard for efficient operation appears to be raised more frequently and rapidly than before. Those who wait for the next boom to reinvest in their operation are increasingly at risk of being left behind. For graziers, exploring the low-input production system under MIG can risk forgoing an unexpectedly large share of outputs. Rapid reductions in output may in part be a consequence of complying with organic production standards (e.g., about a quarter of the graziers in our sample produced organic milk in all or some of the survey years), which can explain particularly rapid declines in efficiency among graziers. The current analysis ignores the difference in milk quality for the sake of comparability between the two systems.

Turning to the coefficient estimate for the heat index, we find little evidence that warmer summer temperatures negatively affect dairy production of efficient or less-than-efficient producers in Maryland, a result generally consistent with a cross-sectional analysis by Key and Sneeringer (2014). Under multiple climate change scenarios, those authors predict that the annual fluctuation of summer temperatures can on average decrease dairy production across states by 0.60 percent to 1.35 percent by 2030 , with varying degrees ranging from less than 0.5 percent in Idaho to about 2.0 percent to 4.5 percent in Texas. Their prediction suggests a very limited impact of about 0.60 percent to 1.00 percent in Pennsylvania, a neighboring state of Maryland.

As for producer characteristics, we find that farm ownership suggests higher efficiency, whereas the impact of having off-farm income is mixed. Higher efficiency for owner-operators in dairy operation is previously reported in Mayen, Balagtas and Alexander (2010). The renter-operator may have lower incentives to invest in on-site production facilities or rent land of 
lower qualities. In our estimate, having off-farm income is associated with lower efficiency among confinement operations but not among graziers. Theoretical prediction of this effect would be ambiguous, given the complexity of the decision to work off-farm that can be influenced by operator's talents in nonfarming activities as well as his/her tolerance to downside income risks.

In the relevant literature, previous studies find that technical efficiency is associated with operational scale (Kumbhakar, Ghosh, and McGuckin 1991, Tauer and Mishra 2006 Byma and Tauer 2010, Key and Sneeringer 2014,); the share of total forage purchases (Mosheim and Lovell, 2009, Cabrera, Solís and del Corral 2010, Mayen, Balagtas and Alexander 2010); the use of total mixed ration (TMR) and daily milking frequency of three times or higher (Cabrera, Solís and del Corral 2010); producer's education (Stefanou and Saxena 1988, Kumbhakar 1993, Byma and Tauer 2010); producer's experience (Stefanou and Saxena 1988 Mosheim and Lovell 2009); managerial ability, measured by producer's subjective value of labor or by lagged net income (Byma and Tauer 2010); the proportion of irrigated area (Kompas and Che 2006); the use of consulting services (Mukherjee, Bravo-Ureta and De Vries 2013); and a share of family-labor in the total-labor input (Cabrera, Solís and del Corral 2010). Also, the output of efficient producers may increase with the use of recombinant bovine somatotropin (rBST) (Cabrera, Solís and del Corral 2010; Mukherjee, Bravo-Ureta and De Vries 2013) and the presence of off-farm income (Kumbhakar 1993 Mayen, Balagtas and Alexander., 2010). Some of these characteristics describe the attributes of typical large-scale confinement operations. To be competitive, dairy producers of smaller scales need to keep pace with rising industry standards set by large dairies and, whenever possible, learn from their efficient peers.

\section{Conclusions}

Amid the increasing consolidation of U.S. dairy production, MIG has been gaining popularity among small- to medium-scale dairies as a low-input, lowoutput system. This article investigates the nature of technological progress and the technical efficiency of the producer using data on Maryland dairy farms during 1995-2009, a period in which confinement dairies scaled up their operations across the country. On average, technology progressed at 1.21 percent per year for conventional confinement operators and 0.59 percent per year for MIG dairies. Given the difference in the rate of technical change, increased research and development in MIG is needed if it is to be a viable alternative to the confinement dairy system. Examples include investigations into improved breeds of grazing cows, high-yielding varieties of forage crops, and pasture management specific to local microclimates. Additionally, the declining average efficiency for both dairy systems needs to be addressed, for instance, through extension programs that support technology adoption. 
On the technical side, by building on the concept of MPI decomposition in a regression framework, we have developed a novel approach to analysis of productivity changes. The method can be used to study production heterogeneity such as the influence of production environments across geographical regions or the impacts of regulations at various phases of implementation. Investigating the properties of the proposed estimator and extending its concept are left for future research. One particular area to add would be an extension of scale efficiency change to the MPI decomposition, which was not pursued in this article due to the limited range of observed operational scales in our data.

\section{References}

Barnard, F.L., Ellinger, P.N., and Wilson, C.A. 2010. "Measurement issues in assessing farm profitability through cash tax returns." Journal of the ASFMRA 207-217.

Battese, G.E. 2002. "Technology gap, efficiency, and a stochastic metafrontier function." Journal of Business and Economics 1(2): 87-93.

Battese, G.E. and Coelli, T.J. 1992. "Frontier production functions, technical efficiency and panel data: With application to paddy farmers in India." Journal of Productivity Analysis 3(1): 153-169.

Battese, G.E. and Coelli, T.J. 1995. "A model for technical inefficiency effects in a stochastic frontier production function for panel data." Empirical Economics 20(2): 325-332.

Battese, G.E., Rao, D.S.P., and O’Donnell, C.J. 2004. "A metafrontier production function for estimation of technical efficiencies and technology gaps for firms operating under different technologies." Journal of Productivity Analysis 21(1): 91-103.

Bishop, P.L., Hively, W.D., Stedinger, J.R., Rafferty, M.R., Lojpersberger, J.L., and Bloomfield, J.A. 2005. "Multivariate analysis of paired watershed data to evaluate agricultural best management practice effects on stream water phosphorus." Journal of Environmental Quality 34(3): 1087-1101.

Blayney, D. 2002. "The Changing Landscape of U.S. Milk Production." U.S. Department of Agriculture, Washington, DC.

Byma, J.P. and Tauer, L.W. 2010. "Exploring the role of managerial ability in influencing dairy farm efficiency." Agricultural and Resource Economics Review 39(3): 505-516.

Cabrera, V., Solís, D., and del Corral, J. 2010. "Determinants of technical efficiency among dairy farms in Wisconsin." Journal of Dairy Science 93(1): 387-393.

Caudill, S.B. and Ford, J.M. 1993. "Biases in frontier estimation due to heteroscedasticity." Economics Letters 41(1): 17-20.

Caves, D.W., Christensen, L.R., and Diewert, W.E. 1982. "Multilateral comparisons of output, input, and productivity using superlative index numbers." The Economic Journal 92(365): 73-86.

Chen, Z. and Song, S. 2008. "Efficiency and technology gap in china's agriculture: A regional metafrontier analysis." China Economic Review 19(2): 287-296.

Cornwell, C., Schmidt, P., and Sickles, R.C. 1990. "Production frontiers with cross-sectional and timeseries variation in efficiency levels." Journal of Econometrics 46(12): 185-200.

Cuesta, R.A. 2000. "A production model with firm-specific temporal variation in technical inefficiency: With application to Spanish dairy farms." Journal of Productivity Analysis 13(2): 139-158.

Dartt, B.A., Lloyd, J.W., Radke, B.R., Black, J.R., and Kaneene, J.B. 1999. "A comparison of profitability and economic efficiencies between management-Intensive grazing and conventionally managed dairies in Michigan." Journal of Dairy Science 82(11): 2412-2420.

Diewert, W.E. 1976. "Exact and superlative index numbers." Journal of Econometrics 4(2): 115-145. 
DiGiacomo, G., Iremonger, C.J., Kemp, L., van Schaik, C., and Murray, H. 2001. "Sustainable Farming Systems: Demonstrating Environmental and Economic Performance." Report, St. Paul, MN: Minnesota Institute for Sustainable Agriculture.

Elbehri, A. and Ford, A. 1995. "Economic analysis of major dairy forage systems in Pennsylvania: the role of intensive grazing." Journal of Production Agriculture 4: 501-507.

Färe, R., Grosskopf, S., Norris, M., and Zhang, Z. 1994. "Productivity growth, technical progress, and efficiency change in industrialized countries." The American Economic Review 84(1): 66-83.

Gloy, B.A., Tauer, L.W., and Knoblauch, W. 2002. "Profitability of grazing versus mechanical forage harvesting on New York dairy farms." Journal of Dairy Science 85(9): 2215-2222.

Hadri, K. 1999. "Estimation of a doubly heteroscedastic stochastic frontier cost function." Journal of Business \& Economic Statistics 17(3): 359.

Hadri, K., Guermat, C., and Whittaker, J. 2003. "Estimation of technical inefficiency effects using panel data and doubly heteroscedastic stochastic production frontiers." Empirical Economics 28(1): 203-222.

Hanson, J., Johnson, D., Lichtenberg, E., and Minegishi, K. 2013. "Competitiveness of management-intensive grazing dairies in the mid-Atlantic region from 1995 to 2009." Journal of Dairy Science 96(3): 1894-1904.

Johnson, A.L. and Kuosmanen, T. 2011. "One-stage estimation of the effects of operational conditions and practices on productive performance: Asymptotically normal and efficient, root-n consistent StoNEZD method." Journal of Productivity Analysis 36(2): 219-230.

Karagiannis, G., Midmore, P., and Tzouvelekas, V. 2002. "Separating technical change from time-varying technical inefficiency in the absence of distributional assumptions." Journal of Productivity Analysis 18(1): 23-38.

Kerstens, K. and Van de Woestyne, I. 2014. "Comparing Malmquist and Hicks-Moorsteen productivity indices: Exploring the impact of unbalanced vs. balanced panel data." European Journal of Operational Research 233(3): 749-758.

Key, N. and Sneeringer, S. 2014. "Potential effects of climate change on the productivity of U.S. dairies." American Journal of Agricultural Economics 96(4): 1136-1156.

Khanal, A.R., Gillespie, J., and MacDonald, J. 2010. "Adoption of technology, management practices, and production systems in US milk production." Journal of Dairy Science 93 (12): 6012-6022.

Kneip, A., Simar, L., and Wilson, P.W. 2015. "When bias kills the variance: Central limit theorems for DEA and FDH efficiency scores." Econometric Theory 31(02): 394-422.

Kompas, T. and Che, T. N. 2006. "Technology choice and efficiency on Australian dairy farms." Australian Journal of Agricultural and Resource Economics 50(1): 65-83.

Kriegel, T. and Frank, G. 2005. "A ten-year economic look at Wisconsin dairy systems." Madison, WI: Center for Dairy Profitability.

Kumbhakar, S.C. 1990. "Production frontiers, panel data, and time-varying technical inefficiency." Journal of Econometrics 46(12): 201-211.

Kumbhakar, S.C. 1993. "Short-run returns to scale, farm-size, and economic efficiency." The Review of Economics and Statistics 75(2): 336-341.

Kumbhakar, S.C., Ghosh, S., and McGuckin, J.T. 1991. "A generalized production frontier approach for estimating determinants of inefficiency in U.S. dairy farms." Journal of Business \& Economic Statistics 9(3): 279-286.

Kumbhakar, S.C., Tsionas, E.G., and Sipilinen, T. 2009. "Joint estimation of technology choice and technical efficiency: An application to organic and conventional dairy farming." Journal of Productivity Analysis 31(3): 151-161.

Lee, Y.H. and Schmidt, P. 1993. "A production frontier model with flexible temporal variation in technical efficiency." In Fried, H.O., Lovell, C.A.K., and Schmidt, P., eds, The Measurement of Productive Efficiency: Techniques and Applications: Techniques and Applications p. 442. Oxford University Press. 
Mayen, C.D., Balagtas, J.V., and Alexander, C.E. 2010. "Technology adoption and technical efficiency: Organic and conventional dairy farms in the United States." American Journal of Agricultural Economics 92(1): 181-195.

McBride, W. and Green, C. 2009. "Characteristics, Costs, and Issues for Organic Dairy Farming." U.S. Department of Agriculture, Washington, DC.

McDonald, J., O’Donoghue, E., McBride, W., Nehring, R., Sandretto, C., and Mosheim, R. 2007. "Profits, Costs, and the Changing Structure of Dairy Farming." U.S. Department of Agriculture, Washington, DC.

Moreira, V.H. and Bravo-Ureta, B.E. 2010. “Technical efficiency and metatechnology ratios for dairy farms in three southern cone countries: a stochastic meta-frontier model." Journal of Productivity Analysis 33(1): 33-45.

Mosheim, R. and Lovell, C.K. 2009. "Scale economies and inefficiency of U.S. dairy farms." American Journal of Agricultural Economics 91(3): 777-794.

Mukherjee, D., Bravo-Ureta, B.E., and De Vries, A. 2013. "Dairy productivity and climatic conditions: econometric evidence from south-eastern United States." Australian Journal of Agricultural and Resource Economics 57(1): 123-140.

Nehring, R., Gillespie, J., Sandretto, C., and Hallahan, C. 2009. "Small U.S. dairy farms: can they compete?" Agricultural Economics 40(s1): 817-825.

Nelson, K.C., Brummel, R.F., Jordan, N., and Manson, S. 2014. "Social networks in complex human and natural systems: The case of rotational grazing, weak ties, and eastern US dairy landscapes." Agriculture and Human Values 31(2): 245-259.

O'Donnell, C.J., Rao, D.S.P., and Battese, G.E. 2008. "Metafrontier frameworks for the study of firm-level efficiencies and technology ratios." Empirical Economics 34(2): 231-255.

Roll, K.H. 2013. "Measuring performance, development and growth when restricting flexibility." Journal of Productivity Analysis 39(1): 15-25.

Rust, J., Sheaffer, C., Eidman, V., Moon, R., and Mathison, R. 1995. "Intensive rotational grazing for dairy cattle feeding." American Journal of Alternative Agriculture 10(04): 147-151.

Samuelson, P.A. and Swamy, S. 1974. "Invariant economic index numbers and canonical duality: Survey and synthesis." The American Economic Review 64(4): 566-593.

Schmidt, P. and Sickles, R. C. 1984. "Production frontiers and panel data." Journal of Business \& Economic Statistics 2(4): 367-374.

Soriano, F.D., Polan, C.E., and Miller, C.N. 2001. "Supplementing pasture to lactating Holsteins fed a total mixed ration diet." Journal of Dairy Science 84(11): 2460-2468.

Stefanou, S.E. and Saxena, S. 1988. "Education, experience, and allocative efficiency: A dual approach." American Journal of Agricultural Economics 70(2): 338.

Tauer, L.W. and Mishra, A.K. 2006. "Dairy farm cost efficiency." Journal of Dairy Science 89(12): 4937-4943.

Taylor, J. and Foltz, J.D. 2006. "Grazing in the dairy state: Pasture use in the Wisconsin dairy industry, 1993-2003." University of Wisconsin-Madison.

Tozer, P.R., Bargo, F., and Muller, L.D. 2003. "Economic analyses of feeding systems combining pasture and total mixed ration." Journal of Dairy Science 86(3): 808-818.

Tucker, W.B., Rude, B.J., and Wittayakun, S. 2001. “Case study: Performance and economics of dairy cows fed a corn silage-based total mixed ration or grazing annual ryegrass during mid to late lactation." The Professional Animal Scientist 17(3): 195-201.

Wang, H.-j. and Schmidt, P. 2002. "One-step and two-step estimation of the effects of exogenous variables on technical efficiency levels." Journal of Productivity Analysis 18 (2): 129-144.

White, S.L., Benson, G.A., Washburn, S.P., and Green, J.T. 2002. "Milk production and economic measures in confinement or pasture systems using seasonally calved Holstein and Jersey cows." Journal of Dairy Science 85(1): 95-104.

Winsten, J.R., Kerchner, C., Richardson, A., Lichau, A., and Hyman, J. 2010. "Trends in the northeast dairy industry: Large-scale modern confinement feeding and managementintensive grazing." Journal of Dairy Science 93(4): 1759-1769. 


\section{Appendix A. Robustness}

Table A.1. Marginal Effect Estimates: Panel-Consistent Standard Errors (PCSE)

\begin{tabular}{|c|c|c|c|c|}
\hline & \multicolumn{2}{|c|}{ Confinement } & \multicolumn{2}{|c|}{ Graziers } \\
\hline & (1) & (2) & (3) & (4) \\
\hline & In TGR & $\ln \mathrm{TE}$ & In TGR & $\ln \mathrm{TE}$ \\
\hline \multirow[t]{2}{*}{ Year } & $1.21^{* * *}$ & $-0.56^{* * *}$ & $0.59^{* * *}$ & $-1.81^{* * *}$ \\
\hline & $(0.11)$ & $(0.15)$ & $(0.08)$ & $(0.31)$ \\
\hline \multirow[t]{2}{*}{ Heat Index } & -0.16 & 0.35 & -0.12 & -0.81 \\
\hline & $(0.29)$ & $(0.37)$ & $(0.21)$ & $(0.89)$ \\
\hline \multirow[t]{2}{*}{ Farm Ownership } & & $3.16^{* *}$ & & $7.08^{* *}$ \\
\hline & & $(1.30)$ & & $(3.05)$ \\
\hline \multirow[t]{2}{*}{ Off-farm Income } & & $-5.40 * *$ & & -3.62 \\
\hline & & $(2.27)$ & & $(3.42)$ \\
\hline \multirow[t]{2}{*}{ Constant } & $-2431.94^{* * *}$ & $1102.91^{* * *}$ & $-1188.00^{* * *}$ & $3593.15^{* * *}$ \\
\hline & $(230.48)$ & $(298.26)$ & $(166.27)$ & $(625.48)$ \\
\hline Adj. R Squared & 0.836 & 0.599 & 0.427 & 0.583 \\
\hline
\end{tabular}

1. Statistical significance: ${ }^{* * *} \alpha=0.01,{ }^{* *} \alpha=0.05,{ }^{*} \alpha=0.1$.

2. Panel-consistent standard errors are used to allow for contemporaneous correlations for a given year. 
Table A.2. Marginal Effect Estimates: Frontiers with Non-cumulative Data Points

\begin{tabular}{|c|c|c|c|c|}
\hline & \multicolumn{2}{|c|}{ Confinement } & \multicolumn{2}{|c|}{ Graziers } \\
\hline & $\begin{array}{c}\text { (1) } \\
\text { ln TGR }\end{array}$ & $\begin{array}{c}\text { (2) } \\
\ln \mathrm{TE}\end{array}$ & $\begin{array}{c}\text { (3) } \\
\text { ln TGR }\end{array}$ & $\begin{array}{c}\text { (4) } \\
\ln T E\end{array}$ \\
\hline \multirow[t]{2}{*}{ Year } & $1.09 * * *$ & $-0.54^{* * *}$ & $0.69^{* * *}$ & $-2.17^{* * *}$ \\
\hline & $(0.15)$ & $(0.12)$ & $(0.14)$ & $(0.26)$ \\
\hline \multirow[t]{2}{*}{ Heat Index } & -0.16 & 0.28 & 0.01 & -0.60 \\
\hline & $(0.33)$ & $(0.39)$ & $(0.48)$ & $(0.77)$ \\
\hline \multirow[t]{2}{*}{ Farm Ownership } & & $5.57^{* * *}$ & & -2.63 \\
\hline & & (1.09) & & $(2.32)$ \\
\hline \multirow[t]{2}{*}{ Off-farm Income } & & $-5.99 * * *$ & & 4.70 \\
\hline & & $(2.13)$ & & $(3.15)$ \\
\hline \multirow[t]{2}{*}{ Constant } & $-2192.51^{* * *}$ & $1051.33^{* * *}$ & $-1404.13^{* * *}$ & $4324.53^{* * *}$ \\
\hline & (292.99) & $(231.01)$ & $(290.25)$ & (519.78) \\
\hline Adj. R Squared & 0.791 & 0.68 & 0.622 & 0.586 \\
\hline
\end{tabular}

1. Statistical significance: ${ }^{* * *} \alpha=0.01,{ }^{* *} \alpha=0.05,{ }^{*} \alpha=0.1$.

2. Technological frontier for each year is estimated using observations of the concurrent year (as opposed to observations up to the concurrent year).

Table A.3. Marginal Effect Estimates: No Bias-corrections

\begin{tabular}{|c|c|c|c|c|}
\hline & \multicolumn{2}{|c|}{ Confinement } & \multicolumn{2}{|c|}{ Graziers } \\
\hline & $\begin{array}{c}\text { (1) } \\
\text { ln TGR }\end{array}$ & $\begin{array}{c}\text { (2) } \\
\ln \mathrm{TE}\end{array}$ & $\begin{array}{c}\text { (3) } \\
\text { ln TGR }\end{array}$ & $\begin{array}{c}\text { (4) } \\
\ln T E\end{array}$ \\
\hline \multirow[t]{2}{*}{ Year } & $1.32^{* * *}$ & $-0.66^{* * *}$ & $0.53^{* * *}$ & $-1.67^{* * *}$ \\
\hline & $(0.13)$ & $(0.12)$ & $(0.07)$ & $(0.27)$ \\
\hline \multirow[t]{2}{*}{ Heat Index } & 0.00 & 0.17 & -0.18 & -0.87 \\
\hline & $(0.26)$ & $(0.43)$ & $(0.21)$ & $(0.94)$ \\
\hline \multirow[t]{2}{*}{ Farm Ownership } & & $2.63^{* *}$ & & 2.90 \\
\hline & & (1.29) & & $(3.05)$ \\
\hline \multirow[t]{2}{*}{ Off-farm Income } & & -3.00 & & 0.30 \\
\hline & & $(2.12)$ & & $(3.36)$ \\
\hline \multirow[t]{2}{*}{ Constant } & $-2642.27^{* * *}$ & $1305.61^{* * *}$ & $-1063.11^{* * *}$ & $3325.68^{* * *}$ \\
\hline & $(262.67)$ & $(238.60)$ & $(150.00)$ & (547.59) \\
\hline Adj. R Squared & 0.839 & 0.387 & 0.312 & 0.374 \\
\hline
\end{tabular}

1. Statistical significance: ${ }^{* * *} \alpha=0.01,{ }^{* *} \alpha=0.05,{ }^{*} \alpha=0.1$.

2. Bias-correction step is omitted. 
Table A.4. Marginal Effect Estimates: DEA under Constant Returns to Scale

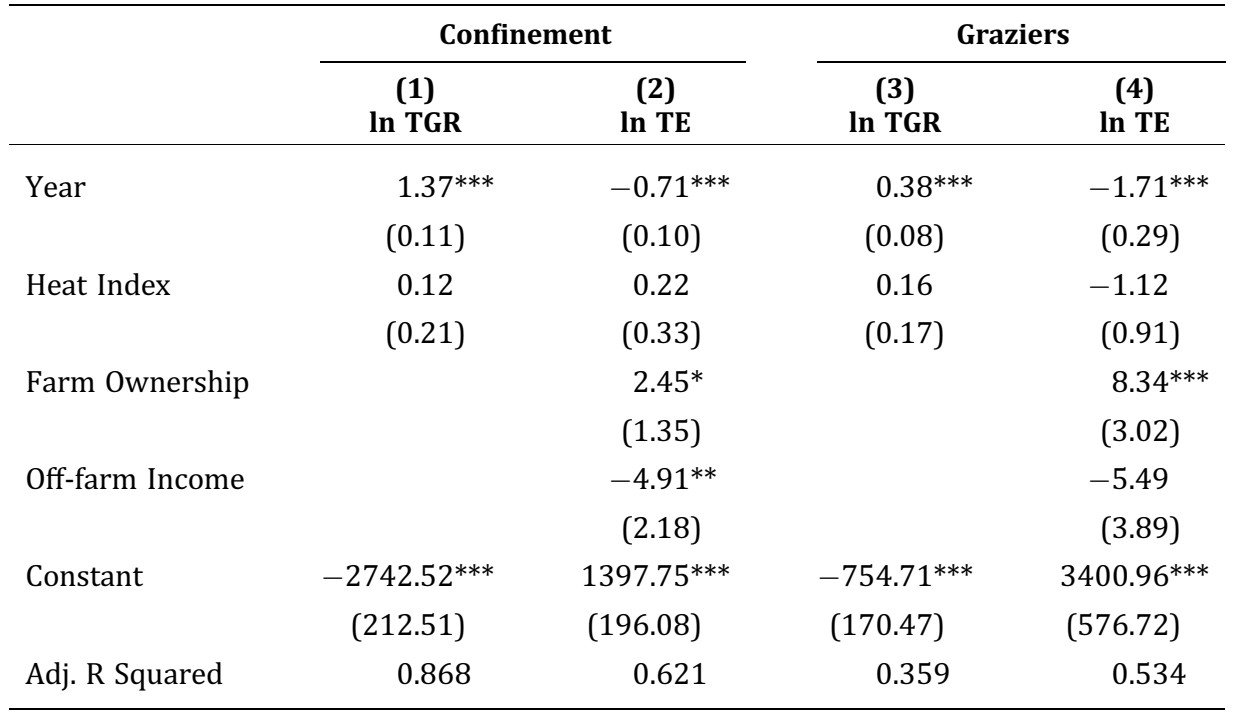

1. Statistical significance: ${ }^{* * *} \alpha=0.01,{ }^{* *} \alpha=0.05,{ }^{*} \alpha=0.1$.

2. DEA is estimated under the constant returns to scale (CRS) assumption.

\section{Appendix B. Parametric Frontier Estimation}

We estimate parametric frontiers that are comparable to the semi-parametric frontier in (2). Consider a time-specific Cobb-Douglas production function with an efficiency component $u_{i t}$ and a stochastic component $v_{i t}$;

$$
\begin{aligned}
& \ln f_{t}^{S F}\left(\boldsymbol{x}_{i t} ; \boldsymbol{w}_{t}\right)=\sum_{l} \alpha_{t l} \ln x_{l, i t}+\beta^{f}\left(\boldsymbol{w}_{t}, t\right)-u_{i t}+v_{i t} \\
& \quad \text { with } u_{i t}=\boldsymbol{z}_{i t} \boldsymbol{\delta}^{u}+\beta^{u}\left(\boldsymbol{w}_{t}, t\right)+\eta_{i t} \geq 0
\end{aligned}
$$

where functions $\beta^{f}\left(\boldsymbol{w}_{t}, t\right)$ and $\beta^{u}\left(\boldsymbol{w}_{t}, t\right)$ are specified as either time-specific intercepts or the combinations of linear time trends and parametric functions of $\boldsymbol{w}_{t}$. Once the equation (B.1) is estimated, we predict $\widehat{T G R}\left(\boldsymbol{x}_{i t}, y_{i t} ; t\right)$ from technological parameters and $\widehat{T E}\left(x_{i t}, y_{i t} ; t\right)=\exp \left(E\left[-u_{i t} \mid v_{i t} \widehat{-u_{i t}}\right]\right)$ from the residual distribution and re-parametrize them according to specification (3). The two-stage estimation through (B.1) and (3) accommodates flexible 
specifications for $\beta^{f}\left(\boldsymbol{w}_{t}, t\right)$ and $\beta^{u}\left(\boldsymbol{w}_{t}, t\right)$, which helps identify TC and TEC without imposing strong distributional assumptions on the error structure. ${ }^{18}$

We estimate (B.1) using several specifications that differ in assumptions on inefficiency $u_{i t}$. Following two common specifications of stochastic frontier analysis (SFA), we estimate the efficiency component model of Battese and Coelli (1995) (i.e., $u_{i t} \sim N^{+}\left(\mu_{u}\left(\mathbf{z}_{i t}, \boldsymbol{w}_{t}, t\right), \sigma_{u}^{2}\right)$ ), previously adopted by Tauer and Mishra (2006), Kompas and Che (2006), Nehring et al. (2009), and Mukherjee, Bravo-Ureta and De Vries (2013), and the heteroskedastic inefficiency model of Hadri (1999) (i.e., $u_{i t} \sim N^{+}\left(0, \sigma_{u}^{2}\left(\mathbf{z}_{i t}, \mathbf{w}_{t}, t\right)\right.$ )), employed by Byma and Tauer (2010), Cabrera, Solís and del Corral (2010), Mayen, Balagtas and Alexander (2010), and Key and Sneeringer (2014). ${ }^{19}$ Both cases assume that the residual components $u_{i t}$ and $v_{i t}$ are uncorrelated with $f_{t}^{S F}($.) and with one another. Additionally, we estimate an OLS specification with producer-specific fixed effects, say $\beta_{i}^{u}\left(\mathbf{w}_{t}, t\right)$, and back out parameters of the frontier and efficiency relative to the smallest producer effect (e.g., Schmidt and Sickles, 1984; Cornwell, Schmidt and Sickles, 1990). The OLS specification does not invoke distributional assumptions of SFA but is influenced on the precision of estimated producer effects.

In Table B.1, we selectively report some results for confinement operations among our estimates of equation (B.1) under a range of conceivable specifications. The estimation for graziers was mostly unsuccessful (i.e., failing to converge under SFA). The three specifications (SFA-1, SFA-2, and OLS-1) in the table differ in their parameterizations of inputs (i.e., acreage variables omitted under SFA-1 and SFA-2), time trends (i.e., a linear trend under SFA-1 and time-specific fixed effects under SFA-2 and OLS-1), and efficiency (i.e., mean-shifted efficiency under SFA-1, heteroskedastic efficiency under SFA-2, and producer fixed effects under OLS-1). Two out of three specifications (SFA-1 and OLS-1) result in qualitatively similar estimates of TC and TEC to those obtained under the nonparametric model.

In the current study, many parametric specifications fail to converge or are unable to yield sensible results likely due to the mismatch between the assumptions of SFA and the nature of heterogeneity in our data. Note that this is not an issue of small sample size but is a general limitation of the parametric frontier approach that relies on a presumed shape of the efficiency distribution. The high importance of relative inefficiency to stochastic noise, as well as the large heterogeneity in observed decisions, tends to exacerbate the problem, which may explain particularly unsuccessful estimation for graziers (unreported).

\footnotetext{
18 Our re-parameterization process does not introduce any additional variables through $\boldsymbol{z}_{i t}$, avoiding a well-known problem of inconsistency in the two-stage stochastic frontier model (Wang and Schmidt, 2002).

19 While it was unfit for our data, one may additionally consider heteroskedastic noise, or $v_{i t} \sim N\left(0, \sigma_{v}^{2}\left(\mathbf{z}_{i t}, \boldsymbol{w}_{t}, t\right)\right)$ (e.g., Caudill and Ford 1993, Hadri et al. 2003).
} 
Table B.1. Stochastic Frontier Estimates (Confinement)

\begin{tabular}{|c|c|c|c|c|c|c|}
\hline & \multicolumn{2}{|c|}{ SFA-1 } & \multicolumn{2}{|c|}{ SFA-2 } & \multicolumn{2}{|c|}{ OLS-1 } \\
\hline & $\begin{array}{c}\text { (1) } \\
\text { ln TGR }\end{array}$ & $\begin{array}{c}(2) \\
\ln T E\end{array}$ & $\begin{array}{c}\text { (3) } \\
\text { ln TGR }\end{array}$ & $\begin{array}{c}(4) \\
\ln T E\end{array}$ & $\begin{array}{c}\text { (5) } \\
\ln \mathrm{TGR}\end{array}$ & $\begin{array}{c}(6) \\
\ln T E\end{array}$ \\
\hline \multirow[t]{2}{*}{ Year } & $1.01^{* * *}$ & $-0.62^{* * *}$ & $0.27^{* * *}$ & 0.00 & $1.37^{* * *}$ & $-0.59^{* * *}$ \\
\hline & $(0.07)$ & $(0.16)$ & $(0.07)$ & $(0.11)$ & $(0.05)$ & $(0.21)$ \\
\hline \multirow[t]{2}{*}{ Heat Index } & 0.09 & -0.38 & $0.71^{* * *}$ & $-1.08^{* * *}$ & -0.04 & 0.08 \\
\hline & $(0.16)$ & $(0.38)$ & $(0.17)$ & $(0.26)$ & $(0.15)$ & $(0.47)$ \\
\hline \multirow[t]{2}{*}{ Farm ownership } & & & & 1.02 & & $4.76^{* * *}$ \\
\hline & & & & (1.07) & & $(1.76)$ \\
\hline \multirow[t]{2}{*}{ Off-farm income } & & & & $-6.45^{* * *}$ & & $-8.89^{* *}$ \\
\hline & & & & $(1.91)$ & & $(4.21)$ \\
\hline \multirow[t]{2}{*}{ Constant } & $-2037.37^{* * *}$ & $1218.22^{* * *}$ & $-554.46^{* * *}$ & 4.17 & $-2751.98^{* * *}$ & $1147.73^{* * *}$ \\
\hline & $(133.94)$ & $(312.68)$ & $(134.18)$ & $(210.97)$ & (97.58) & $(422.65)$ \\
\hline R squared & 0.459 & 0.062 & 0.399 & 0.181 & 0.676 & 0.066 \\
\hline TGR/TE Mean & 0.915 & 0.853 & 0.935 & 0.909 & 0.896 & 0.774 \\
\hline TGR/TE SD & 0.0568 & 0.0916 & 0.0449 & 0.0636 & 0.0629 & 0.110 \\
\hline
\end{tabular}

1. Standard errors in parentheses. Statistical significance: ${ }^{* * *} \alpha=0.01,{ }^{* *} \alpha=0.05,{ }^{*} \alpha=0.1$.

2. Frontier: year-specific Cobb-Douglas function for $\log ($ Milk) for each year is estimated. Cow and capital are used as inputs for SFA-1 and SFA-2, and cow, capital, crop acreage, and pasture acreage are used for OLS-1. OLS-1 is a shifted-OLS model where the frontier is defined using the largest producer-fixed effect and the efficiency is defined relative to that effect.

3. Error components: truncated normal with $\mu_{u}$ shifted with year dummies is used for SFA-1; truncated normal with heteroskedastic $\sigma_{u}^{2}$ in terms of year dummies, farm ownership, and off-farm income for SFA-2; and producer-fixed effects for OLS-1. SFA-1 does not include producer characteristics (doing so leads to a convergence problem).

4. The bottom two rows are the first-stage results for mean and s.d. of TGR and TE in expectation respectively (i.e., direct comparison between observed outputs to frontier-output levels).

5. Heat index is the number of days above 30 degrees Celsius, divided by 10 . 